\title{
CULTIVO DE SIRI: perspectivas para o pequeno criador
}

\author{
Crab cultivation: perspective for the small-scale farmer
}

\author{
Marco Antônio Igarashi \\ Bacharel em Aquicultura, Doutor em Engenharia de Pesca, Docente do Departamento de Engenharia de Pesca da Universidade \\ Federal do Ceará (UFC).Fortaleza, CE-Brasil, e-mail: marco.igarashi@mpa.gov.br; igarashi@ufc.br
}

\begin{abstract}
Resumo
Esta revisão descreve o procedimento do cultivo do siri-da-lama (Scylla serrata) e do siri-azul (Callinectes sapidus). O cultivo de siri-da-lama tem sido uma atividade em pequena escala na Ásia. Com os problemas ambientais ocorridos em fazendas de camarão, é necessário encontrar espécies alternativas para cultivo. O siri-da-lama pode ser cultivado com camarão e com o peixe milkfish (Chanos chanos), com sucesso, incrementando as oportunidades econômicas para as comunidades carentes. Proprietários na Ásia descobriram que estocar os viveiros com siri-da-lama foi lucrativo sem qualquer declínio na produção de peixes. Por outro lado, ainda há uma significante quantidade de problemas a serem resolvidos antes de estabelecer o cultivo de C. sapidus em escala comercial.
\end{abstract}

Palavras-chave: Cultivo. Siri. Pequenos criadores. Scylla serrata. Callinectes sapidus.

\begin{abstract}
This review was carried out to describe culture procedures of mud crab (Scylla serrata) and blue crab (Callinectes sapidus). Culture of mud crab S. serrata has been a small-scale activity in Asia. Due to the environmental problems experienced in shrimp farming, it is necessary to create an interest in finding alternative species to culture. The mud crab can be cultured successfully with shrimp and milkfish (Chanos chanos), enhancing economic opportunity as promising alternatives to poor communities. Owners in Asia found that stocking the pond with mud crab was profitable without any decline in the production of fish. On the other hand, still there are significant problems to overcome in the establishment of large-scale culture of $C$. sapidus.
\end{abstract}

Keywords: Cultivation. Crab. Small-scale farmer. Scylla serrata. Callinectes sapidus. 


\section{INTRODUÇÃO}

Os portunídeos possuem um grande potencial para a aquicultura e, entre eles, as espécies que mais se destacam são: Portunus pelagicus, P. trituberculatus, P. sanguinolentus, Charybdis feriata e Scylla serrata (MWALUMA, 2002). S. serrata é a mais cultivada, devido à sua preferência por habitats estuarinos, comportamento menos agressivo e por seu valor comercial (COWAN, 1984).

O cultivo de Scylla é uma atividade tradicional sustentada pelos pescadores artesanais, e o seu cultivo tem provado ser lucrativo em âmbito familiar (OVERTON; MACINTOSH, 1997). O S. serrata é cultivado com sucesso em muitos países do sudeste da Ásia e Austrália, onde alcança altos preços no mercado local e internacional (MWALUMA, 2002).

O sistema de policultivo extensivo, assim como o monocultivo semi-intensivo de $S$. serrata, é praticado em Taiwan em diferentes etapas, tais como a fase de laboratório, berçário e engorda (LEE; WICKINS, 1992). Em sistema de policultivo, a S. serrata tem sido cultivada junto com camarão e milkfish (Chanos chanos) (CHEN, 1976; COWAN, 1984). Nas Filipinas, as espécies têm sido cultivadas em viveiros (SAMONTO; AGBAYANI, 1992; TRINO et al., 1999), assim como em cercadas (BALIAO et al., 1999). Em Bangladesh, essa é uma das mais importantes espécies de siri utilizadas como alimento e na comercialização, sendo cultivada extensivamente em viveiros com camarões (GIASUDDIN; ALAM, 1991) e no mangue (KADOR, 1991). No leste da Malásia, o cultivo em cercada é uma prática comum, na qual a $S$. serrata cresce em seu habitat natural, locais cercados por mangues (CHANG, 1997). Na Indonésia há relatos de policultivo em viveiros com S. serrata, seabass, milkefish e camarão (MWALUMA, 2002).

A população natural de Scylla está em declínio no sudeste da Ásia, devido à sobrepesca e perda do habitat natural, especialmente dos mangues (OVERTON; MACINTOSH, 1997). O problema é que não há siri disponível suficiente como estoque na indústria do cultivo desse animal e no sustento do estoque selvagem (SHELLEY; FIELD, 1999).

Em 2005, a produção mundial da S. serrata foi de 123.127 toneladas, no valor de US\$ 288.048.000 (TACON, 2007). O S. serrata é uma boa alternativa para o cultivo de camarão e um bom candidato na diversificação da aquicultura em atividades em água salobra (BABU et al., 2000).

A introdução de espécies exóticas no Brasil necessita um prévio estudo ambiental (possível impacto), além de licenças ambientais necessárias e/ou autorizações para exercer a atividade, emitida pelas instituições competentes. Portanto, os aspectos éticos e/ou ambientais devem ser adequadamente tratados.

As espécies do gênero Callinectes nativas ou introduzidas se encontram nas costas europeias (WILLIAMS, 1965), Japão (LEMAITRE, 1981), região oriental do Mediterrâneo (CHACE; HOBBS, 1969), África ocidental e ocasionalmente no Indopacífico; na América, espécies nativas do gênero se encontram em ambas as costas e hemisférios (RODRÍGUEZ, 1980). No Brasil, são registradas 21 espécies de siris da família Portunidae (MELO, 1996; MANTELATTO; DIAS, 1999, apud FERNANDES et al., 2006).

Segundo Rodrigues et al. (2001) a bibliografia referente às espécies do gênero Callinectes (principalmente C. sapidus) é extremamente rica, abordando diferentes aspectos da biologia, ecologia e pesca desse grupo. A pesca de siri-azul C. sapidus é uma importante fonte de renda complementar para as famílias de pescadores profissionais artesanais em algumas partes do Brasil. Segundo Torres (2006), o valor de comercialização varia de $\mathrm{R} \$ 9,00$ a $\mathrm{R} \$ 12,00$ por kg e a casquinha do siri é comercializada por aproximadamente $\mathrm{R} \$ 1,00$ a unidade. De acordo com o mesmo autor, a pesca do siri é considerada uma pesca de subsistência e de importância comercial, devido ao baixo custo de gasto com a pescaria e ao alto valor de comercialização.

A técnica de cultivo comercial das nossas espécies não foram estabelecidas, mas muitos dados podem ser utilizados do cultivo de seu similar, siri-da-lama $S$. serrata, para o qual já existe tecnologia produtiva. O cultivo do siri-mole C. sapidus é considerado talvez a alternativa mais viável a ser implantado no Brasil, por trabalhar com espécies nativas e obter um produto com elevado valor comercial. Portanto, o presente artigo reúne informações sobre a reprodução, larvicultura e engorda da C. sapidus e, principalmente, do S. serrata.

Rev. Acad., Ciênc. Agrár. Ambient., Curitiba, v. 7, n. 4, p. 455-467, out./dez. 2009 


\section{Habitat e etapas do desenvolvimento}

A S. serrata habita mangue, boca de rio, baía, estuário e lagoa, onde ocorre uma ampla variação na salinidade (KIFT, 1987). Segundo Jia e Chen (2001), a S. serrata tolera salinidades da água de $5 \%$ a $33,2 \%$ e a salinidade ótima varia de $13,7 \%$ a $26,9 \%$. De acordo com os mesmos autores, quando a salinidade diminui abaixo de 7\%o, eles frequentemente podem cavar buracos para se protegerem das condições adversas do ambiente. Entre as principais fases de desenvolvimento do siri estão: ovo, zoea, megalopa, juvenil e adulto (Figura 1).

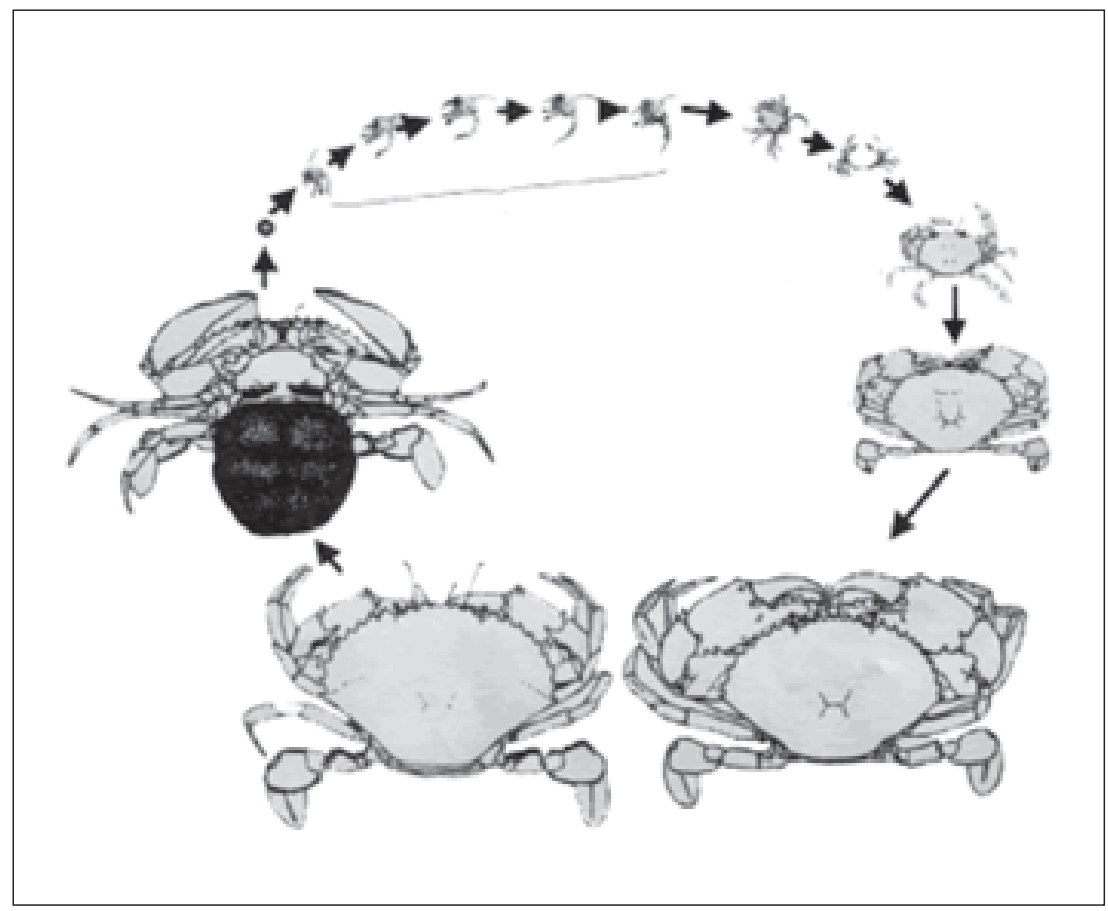

FIGURA 1 - Ciclo de vida do siri do gênero Sylla (HES, 2005) Fonte: HES, 2005

O siri-azul C. sapidus, no sudeste e sul do Brasil, habita desde a região entremarés até 90 metros de profundidade, em baías, estuários e lagoas e com ampla distribuição nos estuários (MELO, 1996). Ambos juvenis e adultos de C. sapidus são capazes de habitar áreas de água doce, assim como altamente salinas, embora a salinidade não seja o maior fator limitante no crescimento, muda ou reprodução (HILL, 2004).

\section{Reprodução}

Estudos na Austrália têm demonstrado que a transição de siris $S$. serrata imaturos para maturidade fisiológica provavelmente ocorre quando os indivíduos possuem a largura de carapaça (CW) (Figura 2) entre 90-110 mm (HEASMAN et al. 1985; KNUCKEY, 1996). Em estudo similar, 50\% dos siris produziram esperma aos $92 \mathrm{~mm}$ CW na África do Sul (ROBERTSON; KRUGER 1994).

Rev. Acad., Ciênc. Agrár. Ambient., Curitiba, v. 7, n. 4, p. 455-467, out./dez. 2009 


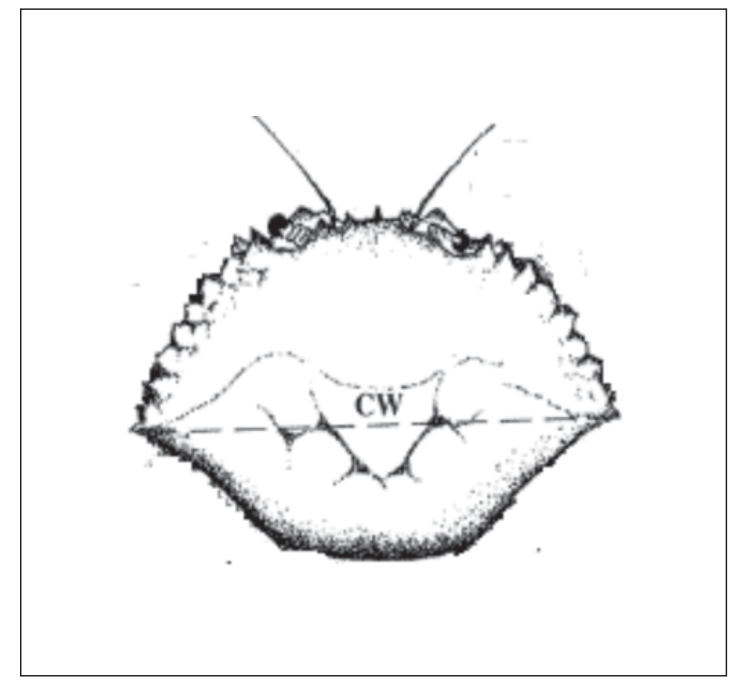

FIGURA 2 - Largura da carapaça (CW) Fonte: SEAFDEC, 2004.
Os reprodutores de $S$. serrata podem ser coletados na natureza ou nos viveiros de cultivo. Segundo Jia e Chen (2001), os indivíduos selecionados devem ser saudáveis, pesando acima de 300 g. De acordo com os mesmos autores, as fêmeas ovígeras com baixa taxa de fertilização e contaminadas pelos parasitas, tais como os ciliados, e por agentes patogênicos causadores de doenças, não são selecionados como reprodutores.

O acasalamento da $S$. serrata ocorre no primeiro ano de vida, após a fêmea passar pela muda precopulatória (RICE, 2003), período em que o exoesqueleto está mole e que dura aproximadamente 48 horas após a muda (PHELAN; GRUBERT, 2007).

No siri $S$. serrata, a fertilização é interna (BABU et al., 2000). Após o acasalamento, a fêmea abandona a água salobra costeira, distanciando-se do ambiente salino para desova (KIFT, 1987). A salinidade ótima varia de $26 \%$ a $31 \%$. O desenvolvimento ovariano é retardado em salinidade mais baixa que 22\%o (JIA; CHEN, 2001)

Segundo Hill (2004), a maturidade do C. sapidus é atingida no segundo ano, com o comprimento da carapaça de 120-170 mm. De acordo com o mesmo autor, no Golfo do México duas desovas por ano são comuns, sendo um período em fevereiro e março, e outro em agosto e setembro.

\section{Fecundidade e período de incubação}

Os ovos de $S$. serrata aderem externamente ao corpo, abaixo do abdômen das fêmeas (Figura 3). A fêmea pode carregar aproximadamente 0,8 a 1,5 milhões de ovos (COWAN, 1983), ou até cerca de 2 milhões de ovos, e com diâmetro de 0,3 mm (PHELAN; GRUBERT, 2007).

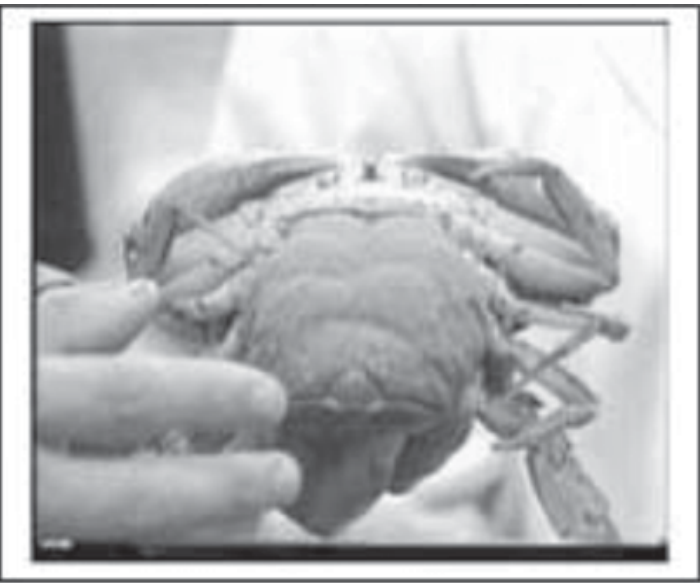

FIGURA 3 - Fêmea ovígera Fonte: JIA; CHEN, 2001.

Rev. Acad., Ciênc. Agrár. Ambient., Curitiba, v. 7, n. 4, p. 455-467, out./dez. 2009 
O período de incubação para a $S$. serrata varia de acordo com a temperatura (Tabela 1), podendo ser de 16 a 17 dias (COWAN, 1983) ou de 10 a 15 dias, a $25-28^{\circ} \mathrm{C}$ (LEE; WICKINS, 1992). Esse período aumenta conforme a temperatura (Tabela 1).

TABELA 1 - Período de incubação de acordo com a temperatura da água

\begin{tabular}{cc}
\hline $\begin{array}{c}\text { Temperatura da água } \\
\left({ }^{\circ} \mathbf{C}\right)\end{array}$ & $\begin{array}{c}\text { Período de incubação(da fertilização à } \\
\text { eclosão dos ovos) - Dias }\end{array}$ \\
\hline 16 & $60-65$ \\
18 & $40-45$ \\
20 & $30-35$ \\
22 & $25-30$ \\
24 & $18-20$ \\
25 & $15-18$ \\
30 & $10-15$ \\
\hline
\end{tabular}

Fonte: JIA; CHEN, (2001).

As fêmeas ovígeras de S. serrata são alimentadas com mexilhão, peixe, poliquetas com $10 \%$ a $15 \%$ da biomassa diariamente. A troca de água é de $50 \%$ a $80 \%$ diariamente.

Segundo Hill (2004), as fêmeas de C. sapidus podem produzir de 2 a 8 milhões de ovos por desova e os ovos são incubados por 14-17 dias. De acordo com o mesmo autor, nessa fase as fêmeas migram para a desembocadura dos estuários, para que a larva possa ser liberada em águas com alta salinidade. As larvas requerem uma salinidade de pelo menos $20 \%$, apresentando baixa sobrevivência em níveis abaixo desse limiar.

\section{Larvas}

A larva planctônica de S. serrata, chamada zoea, possui cinco estágios de desenvolvimento. Esse período de transição, a depender da temperatura da água, pode ocorrer em duas três semanas. Marichamy e Rajapackiam (1991) relataram três a quatro dias de duração para cada um dos cinco estágios de zoea, a $27-30^{\circ} \mathrm{C}$. Nurdiani e Zeng (2007) revelam o período de desenvolvimento larval até o estágio de megalopa, variando de 20,6 a 22,6 dias a $25^{\circ} \mathrm{C}$, com diminuição do período em vários dias no desenvolvimento em altas temperaturas. Os mesmos autores constataram 100\% de mortalidade larval a salinidade 15\%o, e alta sobrevivência em salinidade acima de 20\%o, e foram observadas fêmeas ovígeras migrando para água com alta salinidade distante da praia, antes da desova (QUINITIO et al., 2001).

Os modelos de tanques Kriesels utilizados na criação de larvas de lagostas (HUGHES et al., 1974) podem ser usados acoplados a um sistema de recirculação (HEASMAN; FIELDER, 1983). Segundo Lee e Wickins (1992), é possível cultivar de 10 a 50 larvas/litro. De acordo com os mesmos autores, a taxa de sobrevivência de larvas de até $60 \%$ pode ser obtida na densidade de cultivo de 6 a 50 larvas/litro. A reposição de água é de 30\% a 80\% a cada cinco dias (SEAFEDEC, 2008).

As larvas do S. serrata são alimentadas com rotíferos (Brachionus sp.) no início do período larval e, subsequentemente, com artêmia. Outra possibilidade é alimentar com náuplios de artêmia moído nos primeiros estágios de zoea, e nos estágios posteriores alimentar com até 30 náuplios de artêmia por $\mathrm{mL}$ (LEE; WICKINS, 1992). A artêmia é um dos alimentos comuns utilizados para larvas no cultivo do $S$. serrata (SHELLEY; FIELD, 1999). O Brachionus pode ser ofertado na densidade de 10-15 indivíduos/ mL nos primeiros dez dias (SEAFEDEC, 2008), e nos estágios mais avançados podem ser ofertados peixe moído e carne de bivalve.

Rev. Acad., Ciênc. Agrár. Ambient., Curitiba, v. 7, n. 4, p. 455-467, out./dez. 2009 
Após passar pelos estágios larvais o animal é classificado como megalopa. A megalopa do S. serrata é o primeiro estágio a ter pinças, tornando-se morfologicamente mais parecido com o siri, mas ainda nada ativamente. Alimentam-se de náuplios de artêmia, outras espécies de larvas e dietas frescas ou artificiais. Marichamy e Rajapackiam (1991) relataram um período de 8 a 11 dias para o estágio de megalopa, a $27-30^{\circ} \mathrm{C}$. De acordo com Mann (2005), o estágio de megalopa pode ser de aproximadamente 7 a 10 dias antes de metamorfosear no primeiro estágio de siri juvenil, que possui cerca de $4 \mathrm{~mm}$ de largura e pesa $0,025 \mathrm{~g}$.

A megalopa do S. serrata pode ser transferida para tanques de dez toneladas após 21 dias, na taxa de estocagem de 1-2/litros, sendo alimentados com artêmia por 5 a 7 dias. Após esse período podese adicionar restos de peixe, pequenos camarões e mexilhão (SEAFEDEC, 2008 ).

No estágio de megalopa, podem ser fornecidos peixes moídos e bivalves frescos, mas a sobrevivência frequentemente cai para aproximadamente $20 \%$ no primeiro estágio do siri, devido principalmente ao canibalismo (LEE; WICKINS, 1992). A Figura 4 mostra os estágios do S. serrata desde larva a juvenil.

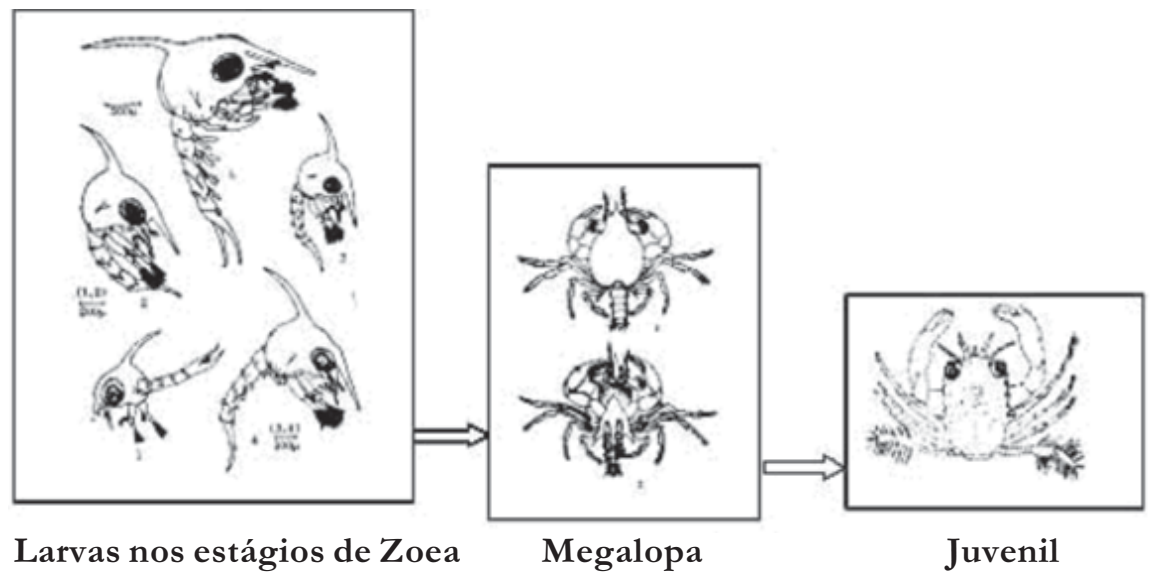

FIGURA 4 - Scylla serrata nos estágios de zoea, megalopa e juvenil Fonte: JIA; CHEN, 2001.

Após 52 dias da eclosão, os juvenis do S. serrata podem ser despescados, embalados e transportados para viveiros ou cercados para engorda (SEAFEDEC, 2008).

A elevação das taxas de mortalidade de larvas de crustáceos decápodes no fim do ciclo de desenvolvimento larval tem sido observada por vários autores que, na maioria das vezes, relacionam esse fenômeno com problemas durante a ecdise (SILVA, 2007). Nesse contexto, Hamasaki et al. (2002) descreveram eventos semelhantes ocorrendo no fim da larvicultura da S. serrata, chamado de MDS ou Molt Death Syndrome. Essa síndrome pode estar relacionada com as deficiências nutricionais.

De acordo com Quinitio et al. (2000), também para o cultivo da S. serrata, o uso de aeração forte esteve relacionado a baixas taxas de sobrevivência.

Ruscoe et al. (2004), num estudo sobre a alimentação de larvas de S. serrata, observaram que é possível cultivar as larvas até a metamorfose para juvenil usando exclusivamente náuplios de artêmia. Porém a sobrevivência, a velocidade de desenvolvimento e o sucesso na metamorfose são incrementados com a inclusão de rotíferos na alimentação inicial (SILVA, 2007).

Costlow e Bookhout (1959) conseguiram completar o ciclo larval de C. sapidus em laboratório, com uma porcentagem de sucesso entre 1\% e 8\%. As larvas de C. sapidus requerem salinidade de pelo menos 20\%o; porém são extremamente eurialinos (HILL, 2004). O desenvolvimento larval da espécie tem

Rev. Acad., Ciênc. Agrár. Ambient., Curitiba, v. 7, n. 4, p. 455-467, out./dez. 2009 
sido difícil, não se estabelecendo a metodologia do cultivo comercial (RODRIGUES; D’INCAO, 2008). Há normalmente sete ou oito estágios de zoea para C. sapidus (GARVINE et al., 1997).

Segundo Zohar et al. (2009), o cultivo intensivo de larvas de C. sapidus (60-140 larvas/litros) desde a eclosão até megalopa em três a quatro semanas, usando espécies de microalgas com alto valor nutricional, rotíferos e náuplios de artêmia enriquecido com omega-3, resultou em $30 \%$ a $80 \%$ de sobrevivência. De acordo com os mesmos autores, as megalopas foram cultivadas até juvenis de $20 \mathrm{~mm}$ (largura média da carapaça), em baixa densidade (5-20/litros), num período de quatro semanas, e a taxa de sobrevivência variou de $10 \%$ a $30 \%$.

\section{Berçário}

Segundo Mann (2005), em laboratório é possível produzir megalopas, ou o primeiro estágio de siri juvenil de $S$. serrata, que podem ser tipicamente criadas em sistema de berçário até um estágio mais avançado, com o tamanho de 10 a $40 \mathrm{~mm}$, antes de serem introduzidas em sistema de engorda. De acordo com o mesmo autor, durante três a seis semanas de cultivo em berçário os siris apresentam hábitos bentônicos e podem ser cultivados com sucesso em redes rasas, tanques ou viveiros na densidade maior que $50 / \mathrm{m}^{2}$. Segundo Lee e Wickins (1992), nesse contexto os siris juvenis de S. serrata são mantidos em viveiro berçário na densidade de 2.000 a $3.000 / \mathrm{m}^{2}$ por duas semanas, em fazendas em Taiwan, que frequentemente possuem quatro a cinco viveiros (na terra), cada um com 15 a $20 \mathrm{~m}^{2}$, contendo $10 \mathrm{~cm}$ de camada de areia de praia. De acordo com os mesmos autores, nesses viveiros a temperatura é controlada pela sombra, salinidade mantida em aproximadamente $20 \%$ e a taxa de água trocada por dia é total, se a água for disponível.

A natureza canibalística dos siris de $S$. serrata pode diminuir a taxa de produção, portanto, é importante a inclusão de habitats adicionais no sistema, tais como redes ou conchas, para melhorar substancialmente a sobrevivência (MANN, 2005). Segundo Zmora et al. (2005), o canibalismo dos juvenis sobre as megalopas tem sido a razão que limita o sucesso dos cultivos realizados em berçários intensivos do C. sapidus.

Quando os siris jovens de S. serrata atingirem o estágio de desenvolvimento II e III (largura da carapaça de: 6-7 mm; peso corporal: $18-32 \mathrm{mg}$ ), eles podem ser transferidos para outros tanques berçários ou engordados em viveiros escavados da fazenda. Mas para serem estocados em viveiros escavados, eles devem ser cultivados por aproximadamente mais dez dias, quando devem ter $13 \mathrm{~mm} e \mathrm{~m}$ largura de carapaça e $5 \mathrm{~g}$ de peso corporal (JIA; CHEN, 2001). Os siris na fase de juvenil são apropriados para serem transferidos para o viveiro de cultivo, para posterior engorda, até atingirem o tamanho comercial de $500 \mathrm{~g}$ (BABU et al., 2000).

\section{Engorda}

O crescimento e a sobrevivência dos siris dependem da densidade ou da taxa de estocagem. Os siris $S$. serrata, após a fase de berçário, podem atingir o tamanho comercial e maturidade em seis a sete meses, comparado com 18 a 24 meses sob condições naturais (MANN, 2005). O tamanho do siri S. serrata na despesca é de 200 a $250 \mathrm{~g}$, com sobrevivência de 50\% a 70\% (MACINTOSH, 1982) e o período de engorda pode ser de três a seis meses (COWAN, 1983).

Em viveiro de $1.200 \mathrm{~m}^{2}$, são estocados aproximadamente $60 \mathrm{~kg}$ de sementes de siri S. serrata (12.000 siris), e $240-480 \mathrm{~kg}$ de siris no tamanho comercial podem ser produzidos (OVERTON; MACINTOSH, 1997). Todavia, o siri pode crescer cerca de $200 \mathrm{~g}$ ou $8 \mathrm{~cm}$ em 4-6 meses e pode-se produzir aproximadamente $340 \mathrm{~kg} / \mathrm{ha}$ anualmente (LEE; WICKINS, 1992).

Segundo Mann (2005), quando os siris $S$. serrata são cultivados até o tamanho comercial em densidades maiores que $3 / \mathrm{m}^{2}$ ocorrem altas perdas, devido à ocorrência de canibalismo. De acordo com o mesmo autor, a taxa de estocagem entre 0,5 e $1,5 / \mathrm{m}^{2}$ fornece uma produtividade e benefícios econômicos mais altos na fase de crescimento até o tamanho comercial.

Rev. Acad., Ciênc. Agrár. Ambient., Curitiba, v. 7, n. 4, p. 455-467, out./dez. 2009 
Em Taiwan, os siris são frequentemente cultivados com Gracilaria (algas), camarão marinho ou peixes (LEE; WICKINS, 1992). Em muitos casos, os siris são capturados como subprodutos de viveiros de cultivo de camarão.

Segundo Hill (2004), o desenvolvimento dos decápodes depende da temperatura, frequência de muda, qualidade e disponibilidade do alimento e estágio de vida.

Os S. serrata são tolerantes à temperatura e são naturalmente eurialinos (os limites da tolerância de temperatura e salinidade são de $12-35^{\circ} \mathrm{C}$ e $2-60 \%$, respectivamente). Siris juvenis e adultos são mais tolerantes à mudança de salinidade e temperatura do que a larva. Segundo Bhiyan e Islam (1981), é mais favorável cultivar S. serrata em salinidades que variam entre 10\% e 50\%o, porém pode ser letal abaixo ou acima de $10 \%$ e $50 \%$, respectivamente. Baliao et al. (1999) sugeriu que a temperatura apropriada para o cultivo pode variar de $25^{\circ} \mathrm{C}$ a $30^{\circ} \mathrm{C}$ (Tabela 2).

TABELA 2 - Crescimento em peso da S. serrata cultivada

\begin{tabular}{cccccc}
\hline Grupos & \multicolumn{5}{c}{ Peso médio do corpo $(\mathrm{g})$} \\
\hline & $\mathbf{1 0}$ dias & $\mathbf{6 0}$ dias & $\mathbf{7 5}$ dias & $\mathbf{9 6}$ dias & $\mathbf{1 8 0}$ dias \\
1 & 5 & - & - & 340 & - \\
2 & - & 120 & 177 & - & 574 \\
\hline
\end{tabular}

Fonte: JIA; CHEN, 2001.

O C. sapidus muda 18 a 22 vezes até atingir a idade adulta (ENGEL, 1958). Segundo Hill (2004) o desenvolvimento tem sido estimado ser de $12 \%$ a $35 \%$ por muda. De acordo com o mesmo autor, temperaturas baixas $\left(<10^{\circ} \mathrm{C}\right)$ previnem a muda e diminuem a taxa de crescimento no siri-azul. Geralmente o desenvolvimento ocorre em temperatura acima de $15^{\circ} \mathrm{C}$, e na maioria das vezes não é afetada pelas condições de salinidade.

O ciclo de mudas do C. sapidus compreende as fases de intermuda, muda e pós-muda. A muda é considerada como a saída do animal da exúvia e a pós-muda pode ser dividida em: soft (duração de 2 a 3 horas), leathery (duração de 2 a 3 horas) e paper shell (duração de 4 a 18 horas) com base na rigidez do espinho lateral (FREEMAN et al., 1987 apud RODRIGUES; D'INCAO, 2008). Na fase soft (carapaça mole) o siri-azul alcança sua maior importância econômica (OESTERLING, 1984). Países como os Estados Unidos e México vêm desenvolvendo a produção e industrialização do sirimole (animais mantidos em cativeiro até que ocorra a ecdise, quando são despescados e processados para comercialização), propiciando um considerável aumento da demanda pelo recurso (LEE e SANFORD, 1962; CUPKA; VAN ENGEL, 1979; BEARDEN et al., 1979; HERNANDEZ; RAMIREZ, 1990). Os pesquisadores estão buscando um sistema de cultivo que viabilize a obtenção do soft crab. No Brasil, Rodrigues (2006) estudou os aspectos do crescimento, em laboratório e no ambiente, de juvenis e adultos do C. sapidus, com o objetivo de desenvolver uma metodologia adequada à obtenção do siri-mole (soft crab).

Segundo Hill (2004), o crescimento do C. sapidus é rápido, com os siris atingindo 70 a 100 mm de comprimento de carapaça no verão. Cadman (1990) observou que o siri-azul desenvolve-se sob condições de laboratório e notou que eles são capazes de mudar e crescer regularmente em temperaturas entre $15^{\circ} \mathrm{C}$ e $30^{\circ} \mathrm{C}$ e salinidades baixas como $3 \%$.

Segundo Hill (2004), a mortalidade de adultos de C. sapidus ocorre sob condições de laboratório quando concentrações de oxigênio dissolvido caem abaixo de $0,6 \mathrm{mg} / \mathrm{L}$ em período acima de 24 horas a temperatura de $24{ }^{\circ} \mathrm{C}$.

Rev. Acad., Ciênc. Agrár. Ambient., Curitiba, v. 7, n. 4, p. 455-467, out./dez. 2009 


\section{Alimentação}

Os siris são onívoros (KIFT, 1987) e se alimentam primariamente de moluscos e crustáceos. No cultivo são alimentados com uma dieta artificial formulada, mas prontamente consomem dietas frescas trituradas, tais como mexilhão ou carne de peixe (MANN, 2005). Segundo Lee e Wickins (1992), a estocagem de $S$. serrata é normalmente feita uma vez ao ano (1.000 siris/ha) no início da estação de engorda (maio - agosto), e mistura de restos de peixe $(1 \mathrm{~kg} / \mathrm{dia} / 30.000$ siris) é fornecida nas duas semanas iniciais de cultivo, após os siris terem alcançado $1 \mathrm{~cm}$ de carapaça (CW) e a taxa de sobrevivência oscila entre aproximadamente 50\% a 70\%. Essa mistura pode ser fornecida a uma taxa de $6 \%$ a $10 \%$ do peso da biomassa por dia.

A taxa de alimentação depende da temperatura e qualidade da água. Segundo Jia e Chen (2001), a temperatura ótima para o crescimento do S. serrata deve ser de $25^{\circ} \mathrm{C}$ e o desenvolvimento é lento em temperatura da água abaixo de $20^{\circ} \mathrm{C}$. O siri morrerá a uma temperatura maior que $32^{\circ} \mathrm{C}$.

Segundo Mann (2005), a salinidade ideal para o crescimento do S. serrata é de aproximadamente $15 \%$ a $25 \%$. De acordo com o mesmo autor, a salinidade não parece ser um fator importante para a sobrevivência, desde que fique acima de $10 \%$ e não exceda $45 \%$.

C. sapidus é onívoro, alimentando-se de invertebrados bentônicos, especialmente moluscos (bivalves e gastrópodes) e crustáceos (ostrácodes, tanaidáceos e restos de decápodes) (OLIVEIR et al., 2006).

\section{CONSIDERAÇÕES FINAIS}

Devido à baixa sobrevivência das larvas e ao longo período para o siri atingir um bom tamanho comercial, sugere-se mais pesquisas no sentido de possibilitar o seu cultivo comercial no Brasil.

A metodologia do cultivo do siri C. sapidus não foi estabelecida. Por isso, deve-se examinar cuidadosamente importantes fatores econômicos e ecológicos para se conservar a fauna e evitar os riscos em potencial das capturas. A captura do siri deve ser executada de maneira sustentável. Esse declínio da população natural pode ser devido à sobrepesca e à perda do ambiente natural, especialmente os mangues.

A taxa de sobrevivência na fase inicial de cultivo de C. sapidus é pequena e ainda não existe a formulação de alimento de baixo custo e eficiente no desenvolvimento dos siris.

Para se estabelecer o cultivo comercial de siris de C. sapidus são necessários o desenvolvimento de técnicas simplificadas, condições controláveis da desova e o cultivo de siris em altas densidades populacionais e resistentes a doenças.

As técnicas estabelecidas para o cultivo de $S$. serrata abrem novos horizontes para a possibilidade de se estabelecer uma metodologia do cultivo comercial de C. sapidus. Até essa metodologia do cultivo de C. sapidus ser determinada, os criadores de siris ainda dependem de estoques naturais em que haja a ocorrência de um grande número de juvenis que sirvam como sementes para realizar a engorda, desde que haja permissão dos órgãos competentes.

\section{REFERÊNCIAS}

BABU, D. E. et al. Larval rearing of mud crabs. Infofish International, Kuala Lumpur, n. 2, p. 30-33, 2000.

BALIAO, D. D. et al. Pen culture of mud crab in mangroves. Aquaculture Extension Manual, Philippine, n. 26, 10 p., 1999.

BEARDEN, C. M. et al. Information on establishing a soft shell crab operation in South Carolina. South Carolina Wildlife Marine Resources Department Education Report, Columbia, v. 1, n. 1, p. 10-21, 1979.

Rev. Acad., Ciênc. Agrár. Ambient., Curitiba, v. 7, n. 4, p. 455-467, out./dez. 2009 
BHUIYAN, A. L.; ISLAM, M. J. Tolerance and distribution of scylla serrata in response to salinity of karnafully river estuary. Bangladesh Journal of Agricultural Sciences, Mymensingh, v. 6, n. 1, p. 7-15, 1981.

CADMAN, L. Some effects of temperature and salinity on the growth of juvenile blue crabs. Bulletin of Marine Science, Miami, v. 46, n. 1, p. 244-255, 1990.

CHACE JR., F. A.; HOOBS, H. H. The freshwater and terrestrial decapod crustaceans of the West Indies with special reference to Dominica. United States National Museum Bulletin, Washington, v. 292, n. 1, p. 1-258, 1969.

CHANG, W. W. Pen culture of mud crabs in the mangrove ecosystems in Sarawak (East Malaysia). Aquaculture Asia, Bangkok, v. 2, n. 4, p. 3-5, 1997.

CHEN, T. P. Crab culture. In: CHEN, L. (Ed.). Aquaculture practices in Taiwan. London: Fishing News Book, 1976, p. 123-128.

COSTLOW Jr., J. D.; BOOKHOUT, C. G. The larval development of Callinectes sapidus Rathbun reared in the laboratory. Biological Bulletin, London, v. 116, n. 3, p. 373-396, 1959.

COWAN, L. Hatchery Production of crabs in Japan. In: INTERNATIONAL CONFERENCE ON WARM WATER CULTURE CRUSTACEA, 1., 1983, Hawaii. Proceedings... Hawaii: Brigham Young University, 1983. p. 215-220.

. Crab farming in Japan, Taiwan and the Philippines. Australia: Queensland Department of Primary Industries, Brisbane, Qld, 1984. (Australia, Information series Q184009).

CUPKA, D. M.; VAN ENGEL, W. A. Proceedings of workshop on soft shell blue crabs. South Carolina Wildlife Marine Resources Department Education Report, Columbia, v. 48, n. 1, p. $1-48,1979$.

ENGEL, W. A. The blue crab and its fishery in Chesapeake Bay. Part 1: reproduction, early development, growth and migration. Commercial Fisheries Review, Washington, v. 20, n. 6, p. $6-17,1958$.

FERNANDES, J. M. et al. Biologia e distribuição temporal de Callinectes ornatus Ordway, 1863 (Crustacea, Portunidae) em uma praia arenosa da Ilha do Frade, Vitória-ES. Boletim do Museu de Biologia Mello Leitão (Nova Série), Santa Tereza, v. 20, n. 1, p. 59-71, 2006.

GARVINE, R., W. et al. Transport and recruitment of blue crab larvae: a model with advection and mortality. Estuarine, Coastal and Shelf Science, Miami, v. 45, n. 1, p. 99-111, 1997.

GIASUDDIN, M.; ALAM, M. F. The mud crab (Scylla serrata) fishery and its bio-economics in Bangladesh. In: ANGEL, C. A. (Ed.). The mud crab: a report on the seminar convened in Surat Thai. Thailand: Proceedings of Bay of Bengal Programme, 1991. p. 29-40.

HAMANAKO EXPERIENCE STATION - HES. Nokogiri gazami. 2005. Disponível em: <http://www.orange.ne.jp/ ulotto/nokogiri.htm>. Acesso em: 15 mar. 2008.

HAMASAKI, K. et al. Mass mortality during etamorphosis to megalops in the seed production of mud crab Scylla serrata (Crustacea, Decapoda, Portunidae). Fisheries Science, Tokyo, v. 68, n. 6, p. 1226-1232, 2002.

HEASMAN, M. P.; FIELDER, D. R. Laboratory spawning and mass rearing of the mangrove crab, (Scylla serrata, Forsskål), from first zoea to first crab stage. Aquaculture, Amsterdam, v. 34, n. 3-4, p. 303-316, 1983. 
HEASMAN, M. P. et al. Mating and spawning in the mud crab, (Scylla serrata, Forsskål) (Decapoda: Portunidae), in Moreton Bay, Queensland. Australian Journal of Marine and Freshwater Research, Melbourne, v. 36, n. 6, p. 773-783, 1985.

HERNANDEZ, T. I.; RAMIREZ, G. J. Obtencion de jaiba suave Callinectes spp. en flotadores de madera en Alvarado. Secretaria de Pesca, Serie Documento de Trabajo, México, v. 16, n. 1, p. 1-22, 1990.

HILL, K. Callinectes sapidus smithsonian marine station at fort piece. 2004. Disponível em: <http://www.sms.si.edu/IRLspec/Callin_sapidu.htm>. Acesso em: 12 maio. 2009.

HUGHES, J. T. et al. A rearing tank for lobster larvae and other aquatic species. Progressive Fish-Culturist, Washington, v. 36, n. 3, p. 129-132, 1974.

JIA, J.; CHEN, J. Sea Farming and sea ranching in China. FAO Fisheries Technical Papers, Rome, v. 1, n. 418 , p. 1-75, 2001.

KADOR, A. Mud crab: a potential aquaculture resource of Bangladesh. In: ANGEL, C. A. (Ed.). The mud crab: a report on the seminar convened in Surat Thai. Thailand: Proceedings of Bay of Bengal Programme, 1991. p. 95-102.

KANAGAWA INTERNATIONAL FISHERIES TRAINING - KIFT. Aquaculture Organism of the World. Japan: Japan International Cooperation Agency - JICA, 1987.

KNUCKEY, I. A. Maturity in male mud crabs, Scylla Serrata, and the use of mating scars as a functional indicator. Journal of Crustacean Biology, San Antonio, v. 16, n. 3, p. 487-495, 1996.

LEE, C. F.; SANFORD, F. B. Soft crab industry. Commercial Fisheries Review, Washington, v. 24, n. 1, p. 10-12, 1962.

LEE, D. O'C.; WICKINS, J. F. Crustacean farming. Oxford: Blackwell Scientific Publications, 1992. $392 \mathrm{p}$.

LEMAITRE JR., R. B. Shallow-water crabs (Decapoda, Brachyura) collected in the southern Caribbean near Cartagena, Colombia. Bulletin of Marine Science, Rickenbacker Causeway, v. 31, n. 2, p. 234-266, 1981.

MACINTOSH, D. J. Fisheries and aquaculture significance of mangrove swamps with particular reference to the Indo-West Pacific Region. In: MUIR, J. F.; ROBERTS, R. J. (Ed.). Recent advances in aquaculture. London: Croom Helm Ltd, 1982. p. 1-84.

MANN, D. Notes on rearing of mud crab (Scylla serrata). Department of Primary Industries and Fisheries. 2005. Disponível em: <http://w ww2.dpi.qld.gov.au/fishweb/2698.html>. Acesso em: 10 jan. 2008.

MARICHAMY, R. S.; RAJAPACKIAM, S. Experiments on larval rearing and seed production of the mud crab (Scylla serrata, Forsskål). In: ANGEL, C. A. (Ed.). The mud crab: a report on the seminar convened in Surat Thai. Thailand: Proceedings of Bay of Bengal Programme, 1991. p. 135-141.

MELO, G. A. S. Manual de identificação dos Brachyura (caranguejo e siri) do Litoral Brasileiro. São Paulo: Plêaide/EDUSP, 1996.

MWALUMA, J. Pen culture of the mud crab Scylla serrata in Mtwapa mangrove system, Kenya. Western Indian Ocean Journal of Marine Sciences, New Delhi, v. 1, n. 2, p. 127-133, 2002.

NURDIANI R.; ZENG, C. Effects of temperature and salinity on the survival and development of mud crab, (Scylla serrata, Forsskål), larvae. Aquaculture Research, Danvers, v. 38, n. 14, p. $1529-1538,2007$. 
OeSTERling, M. J. Manual for Handling and Shedding Blue Crabs (Callinectes sapidus). Virginia: Gloucester Point, 1984.

OLIVEIR, A. et al. Dieta natural do siri-azul Callinectes sapidus (Decapoda, Portunidae) na região estuarina da Lagoa dos Patos, Rio Grande, Rio Grande do Sul, Brasil. Iheringia, Série Zoologia, Porto Alegre, v. 96, n. 3, p. 305-313, 2006. Disponível em: <http://www.scielo.br/pdf/isz/v96n3/ 06.pdf>. Acesso em: 7 maio. 2009.

OVERTON, J. L.; MACINTOSH, D. J. Mud crab culture: prospects for the small scale Asian farmer. Infofish International, Kuala Lumpur, v. 1, n. 5 p. 26-32, 1997.

PHELAN, M. M.; GRUBERT, M. The life cycle of the mud crab. Coastal Research Unit Fisheries, Darwin, v. 1, n. 11, p. 1-4, 2007.

QUINITIO, E. T.; PARADO-ESTEPA, F. D. Transport of Scylla serrata megalopae at various densities and durations. Aquaculture, Amsterdam, v. 185, n. 1/4, p. 63-71, 2000.

QUINITIO, E. T. et al. Seed production of mud crab Scylla serrata juveniles. Asian Fisheries Science, Manila, v. 14, n. 2, p. 161-174, 2001.

RICE, D. Non-native aquatic species in the Gulf of Mexico and South Atlantic region. 2003. Gulf states marine fisheries commission. Disponível em: <http://nis.gsmfc.org/>. Acesso em: 10 Jan. 2008.

ROBERTSON, W. D.; KRUGER, A. Size at maturity, mating and spawning in the portunid crab (Scylla serrata, Forsskål) in Natal, South Africa. Estuarine, Coastal and Shelf Science, London, v. 39, n. 2, p. 185-200, 1994.

RODRIGUES, E. S. et al. Pesca artesanal de siris (crustacea, decapoda, portunidae) na região estuarina de Santos e São Vicente (SP), Brasil. Boletim do Instituto de Pesca, São Paulo, v. 27, n. 1, p. 7-19, 2001.

RODRIGUES, M. A. Callinectes sapidus (Rathbun, 1896) no estuário da lagoa dos Patos. 2006. 83 f. Dissertação (Mestrado em Oceanografia Biológica) - Programa de Pós-Graduação em Oceanografia Biológica da Fundação Universidade Federal do Rio Grande, Rio Grande, 2006.

RODRIGUES, M. A.; D'INCAO, F. Comparação do crescimento entre Callinectes sapidus (Crustacea, Decapoda, Portunidae) coletados em campo e mantidos em condições controladas. Iheringia Série Zoologia, Porto Alegre, v. 98, n. 3, p. 372-378, 2008.

RODRÍGUEZ, G. Los crustáceos decápodos de Venezuela. Caracas: Instituto Venezoelano de Investigationes Científicas, 1980. 494 p.

RUSCOE, I. M. et al. Limiting the use of rotifers to the first zoeal stage in mud crab (Scylla serrata, Forsskål) larval rearing. Aquaculture, Amsterdam, v. 231, n. 1/4, p. 517-527, 2004.

SAMONTO, G. P. B.; AGBAYANI, R. F. Pond culture of mud crab (Scylla serrata): an economic analysis. SEAFDEC-ASIAN Aquaculture, Bangkok, v. 14, n. 2, p. 3-5, 1992.

SEAFDEC - AQUACULTURE DEPARTMENT. External anatomy of a mud crab. 2004. Disponível em: <http://rfdp.seafdec.org.ph/publication/manual/crab/appendix.html>.

SEAFDEC - AQUACULTURE DEPARTMENT. Hatchery and nursery of mud crab. Iloilo: SEAFDEC, 2008. Disponível em: <http://www.seafdec.org.ph/commodities/mudcrab_hatchery.html>. Acesso em: 11 mar. 2008. 
SHELLEY, C.; FIELD, D. The culture of portunid crabs. Infofish International, Kuala Lumpur, v. 1, n. 4, p. 46-49, 1999.

SILVA, U. A. T. Recuperação populacional de caranguejo-uçá (Ucides cordatus, LINNAEUS, 1763), através da liberação de formas imaturas em áreas antropicamente pressionadas. 174 f. Tese (Doutorado em Zoologia) - Curso de Pós-Graduação em Zoologia da Universidade Federal do Paraná, Curitiba, 2007.

TACON, A. G. J. Produção aqüícola global em 2005 e as estimativas da quantidade de ração utilizada. Revista Panorama da Aqüicultura, Rio de Janeiro, v. 17, n. 100, p. 44-29, 2007.

TAGATZ, M. E. Biology of the blue crab, Callinectes sapidus rathbun, in the St. Johns River, Florida. Fishery Bulletin, Seattle, v. 67, n. 1, p. 17-33, 1968.

TORRES, U. Pesca e comercialização do siri-azul Callinectes sapidus no estuário Tramandaã-Armação, Litoral Norte. In: FÓRUM DE PRODUÇÃO CIENTÍFICA, 5., 2006, Torres. Anais... Torres: ICULB, 2006.

TRINO, A. T. et al. Commercial evaluation of monosex pond culture of the mud crab Scylla species at three stocking densities in the Philippines. Aquaculture, Amsterdam, v. 174, n. 1-4, p. 109-118, 1999.

VAN ENGEL, W. A. The blue crab and its fishery in Chesapeake Bay. Part 1. Reproduction, early development, growth and migration. Commercial Fisheries Review, Washington, v. 20, n. 6, p. 6-17, 1958.

WILLIAMS, A. B. Marine decapod crustaceans of the Carolina. Fisheries Bulletin, Seattle, v. 65, n. 1, p. 1-298, 1965.

ZMORA, O. et al. Large-scale juvenile production of the blue crab Callinectes sapidus. Aquaculture, Amsterdam, v. 244, n. 1/4, p. 129-139, 2005.

ZOHAR, Y. et al. The Chesapeake Bay blue crab (Callinectes sapidus): a multidisciplinary approach to responsible stock enhancement. Reviews in Fisheries Science, v. 16, n. 1, p. 24-34. Disponível $\mathrm{em}:<\mathrm{http}: / /$ www.informaworld.com $/ \mathrm{smpp} /$ content $\sim \mathrm{db}=$ all $\sim$ content $=\mathrm{a} 903563522>$. Acesso em: 7 maio 2009. 